\title{
Successful oxygenation during anesthesia induction using a high-flow nasal cannula in a patient with severe hypoxemia due to lung cancer
}

\author{
Hiroyuki Seki ${ }^{*}$, Yoshihiko Deguchi, Tomomi Ogihara and Takashi Ouchi
}

To the Editor,

Tracheal intubation in severe hypoxemia patients remains challenging. Although mask ventilation using an anesthesia circuit can deliver high-concentration oxygen, ventilation must be stopped while attempting tracheal intubation, which may result in deterioration of hypoxemia in respiratory failure patients. Herein, we report a case of successful oxygenation during anesthesia induction using a high-flow nasal cannula (HFNC) in a lung cancer-associated severe hypoxemia patient.

A 64-year-old man $(160 \mathrm{~cm}, 59.2 \mathrm{~kg})$ with a history of upper right lobectomy was scheduled for left lower lobectomy for lung cancer. A week before admission, he presented bloody sputum and exacerbating dyspnea. Preoperative respiratory function tests revealed obstructive respiratory impairment (forced expiratory volume in the first second (FEV1) $1.96 \mathrm{~L}$ and FEV1/forced vital capacity ratio 59.6\%). He was then admitted to our hospital 1 day preoperatively. On admission, the room-air $\mathrm{SpO}_{2}$ was $90 \%$ and dropped to $85-88 \%$ during conversation; it further deteriorated to $82 \%$ with coughing. He had severe chest pain due to pleurisy and could not take a deep breath. In the operating room, he was in the lateral position on the bed, and the $\mathrm{SpO}_{2}$ was $69 \%$. Despite administering $10 \mathrm{~L} / \mathrm{min}$ oxygen using a face mask, the $\mathrm{SpO}_{2}$ did not exceed $90 \%$. We decided to apply a HFNC for anesthesia induction. Three minutes after administering oxygen $\left(50 \mathrm{~L} / \mathrm{min} ; \mathrm{F}_{\mathrm{I}} \mathrm{O}_{2}, 92 \%\right)$ through the HFNC, the $\mathrm{SpO}_{2}$ was elevated to $98 \%$ and maintained at $97-98 \%$. Propofol $(120 \mathrm{mg})$ and rocuronium $(50 \mathrm{mg})$ were administered 4 min later, and the trachea was intubated with a
37-Fr double-lumen tube 2 min after the administration of rocuronium without a drop in the $\mathrm{SpO}_{2}$.

After intubation, the $\mathrm{SpO}_{2}$ remained stable and the surgery was completed without further complications. After extubation, the patient was transferred to the intensive care unit. The $\mathrm{SpO}_{2}$ was maintained at $99-100 \%$ using a facemask $\left(\mathrm{O}_{2}, 5 \mathrm{~L} / \mathrm{min}\right)$, and the patient was transferred to the surgical ward the day after the surgery.

Accurately placing a double-lumen tube in the trachea takes a longer time compared to a standard tube. While attempting tracheal intubation, oxygen cannot be delivered through a facemask, which might cause desaturation, especially in severe hypoxemia patients. While HFNC has been used in critical care medicine, it has recently gained attention for its potential roles in perioperative settings [1-3]. HFNC has several advantages over conventional oxygen devices. First, it can supply high-concentration oxygen without interfering with transoral procedures such as orotracheal intubation. Second, the high flow rate generates low-level positive airway pressure. A previous study demonstrated that HFNC could maintain oxygenation even in apneic patients for up to $30 \mathrm{~min}$ [4]. These HFNC features can be advantageous in cases of tracheal intubation which are expected to take a longer time in severe hypoxemia patients.

In conclusion, HFNC can be useful when tracheal intubation is expected to take a longer time in severe hypoxemia patients.

The patient provided written informed consent for the publication of this case report.

\footnotetext{
* Correspondence: hshiroyukiseki@gmail.com

Department of Anesthesiology, Tokyo Dental College Ichikawa General

Hospital, 5-11-13 Sugano Ichikawa, Chiba 272-8513, Japan
}

\section{Springer Open}

( ) The Author(s). 2020 Open Access This article is licensed under a Creative Commons Attribution 4.0 International License, which permits use, sharing, adaptation, distribution and reproduction in any medium or format, as long as you give appropriate credit to the original author(s) and the source, provide a link to the Creative Commons licence, and indicate if changes were made. The images or other third party material in this article are included in the article's Creative Commons licence, unless indicated otherwise in a credit line to the material. If material is not included in the article's Creative Commons licence and your intended use is not permitted by statutory regulation or exceeds the permitted use, you will need to obtain permission directly from the copyright holder. To view a copy of this licence, visit http://creativecommons.org/licenses/by/4.0/. 
Abbreviation

HFNC: High-flow nasal cannula

\section{Acknowledgements}

Not applicable.

\section{Authors' contributions}

$H S$, YD, and TO participated in the care of the patient. YD obtained consent from the patient. HS prepared the manuscript. All authors read and approved the final manuscript.

\section{Funding}

This case study did not receive any specific grant from funding agencies in the public, commercial, or not-for-profit sectors.

\section{Availability of data and materials}

Not applicable.

Ethics approval and consent to participate

Ethical approval was not required by our institution.

\section{Consent for publication}

The patient provided written informed consent for publication of this case report.

\section{Competing interests}

None

Received: 10 March 2020 Accepted: 1 April 2020

Published online: 07 April 2020

\section{References}

1. Renda T, Corrado A, Iskandar G, Pelaia G, Abdalla K, Navalesi P. High-flow nasal oxygen therapy in intensive care and anaesthesia. Br J Anaesth. 2018. 120:18-27.

2. Kurose H, Seki H, Ideno S, Kato J, Morisaki H. High-flow nasal cannula oxygenation during interventional bronchoscopy in a patient with severe tracheal stenosis. J Clin Anesth. 2018:46:92-3.

3. Deguchi Y, Seki H, Taaki H, Ouchi T. Successful airway and anesthesia management using a high-flow nasal cannula in a fibrodysplasia ossificans progressiva patient during general anesthesia: a case report. A A Practice. 2020;14:75-8

4. Gustafsson IM, Lodenius A, Tunelli J, Ullman J, Jonsson FM. Apnoeic oxygenation in adults under general anaesthesia using transnasal humidified rapid-insufflation ventilatory exchange (THRIVE) - a physiological study. Br J Anaesth. 2017;118:610-7.

\section{Publisher's Note}

Springer Nature remains neutral with regard to jurisdictional claims in published maps and institutional affiliations.

\section{Submit your manuscript to a SpringerOpen ${ }^{\circ}$ journal and benefit from:}

- Convenient online submission

Rigorous peer review

- Open access: articles freely available online

High visibility within the field

- Retaining the copyright to your article 